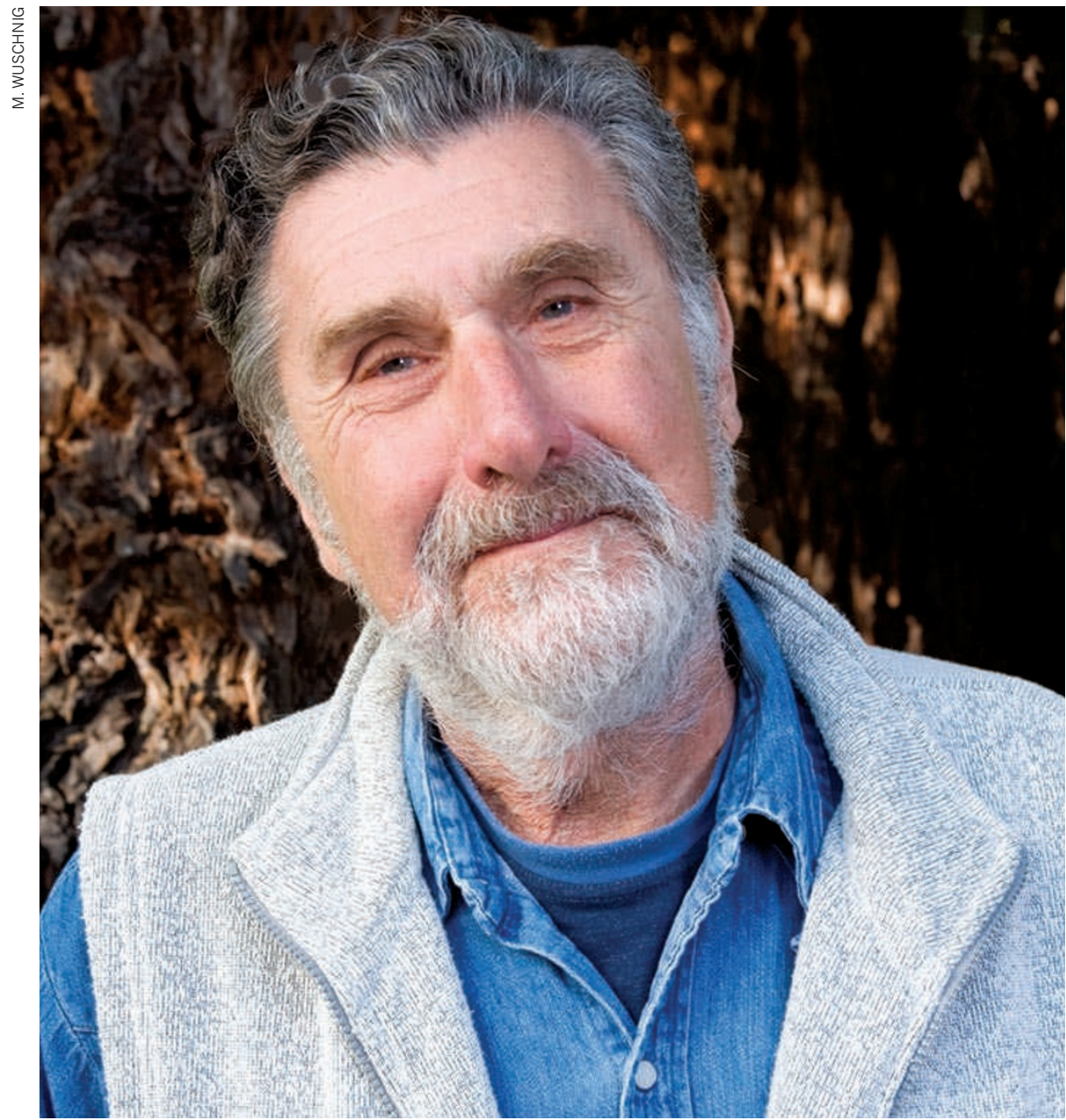

Elliot Aronson has studied the psychology of how people cope with conflicting beliefs and experiences.

PSYCHOLOGY

\title{
A social animal revealed
}

\section{The inner strengths of psychologist Elliot Aronson are on display in his honest autobiography, finds W. F. Bynum.}

S

ocial psychologist Elliot Aronson might not be a household name, but his work is. As author of the landmark book The Social Animal, first published in 1972, he experimentally demonstrated the psychology behind Groucho Marx's famous line: "I refuse to belong to any club that would have me as a member." In Aronson's autobiography, Not By Chance Alone, he applies his scientific insight to his life and its dilemmas.

Aronson is best known among social psychologists for his work on cognitive dissonance, the mechanism by which people cope with conflicting beliefs and experiences by minimizing discrepancies, thus reducing anxiety and tension. Building on the theory of one of his teachers, Leon Festinger, Aronson and his colleagues performed a series of classic experiments that extended its application. Most famously, they showed that the harder it is for people to become part of a group, the more they value membership - no matter how trivial the achievement needed to join.

Aronson has investigated many human traits, including hypocrisy, efficiency, attraction and sexuality. His experiments are cleverly designed and he insists on rigorous standards. His co-authored chapter on experimental methods in the second edition of the Handbook of Social Psychology (Addison-Wesley, 1968) helped to make the field credible as a science.

Experimental social psychology is often criticized for relying on deceit and theatricality. Its test subjects must not know the point of the enterprise. Aronson believes that such experimental design is justified because it gives real insight into human behaviour. He describes how social psychologist Stanley Milgram discussed with him early plans for a controversial 'obedience to authority' experiment, in which subjects were told to inflict what they thought were increasing levels of pain on other participants by administering fake electric shocks. Milgram's results - that most subjects inflicted 'pain' on others when commanded - gener-

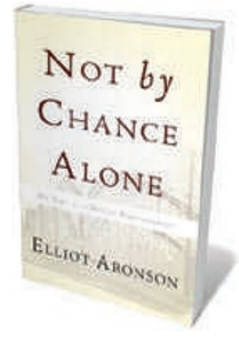

Not by Chance Alone: My Life as a Social Psychologist ELLIOT ARONSON Basic Books: 2010. 304 pp. £15.99 ated ire from both the public and the scientific community. Aronson defends the tests as showing how ordinary citizens might have acted in the Nazi era.

Much of the autobiography is devoted to Aronson's career at several US universities, including Stanford University, California; the University of Minnesota in Minneapolis; the University of Texas at Austin and the University of California, Santa Cruz, where he is an emeritus professor today. $\mathrm{He}$ also taught at Harvard for a couple of years, from 1959 to 1961, but he liked the place little more than the place liked him. He valued the quality of the Harvard students, but felt that Ivy League elitism was not for him. As a Jewish academic, he was also realistic about the chances of getting tenure at a time when formal quotas limiting admission of ethnic minorities were still rife. He left Harvard before he had to.

The fact that he got there at all is a tribute to his personal qualities. His family was dysfunctional. His father coped badly with the loss of his small shop during the depression of the 1930s, and struggled with the dynamics of family life and the insecurities of being an inadequate breadwinner. Aronson writes eloquently about the ambivalence within him that his father's remoteness caused. He had to work hard not to become like his father - prone to storming out of the house when nagged by his wife, or to react with loud violence. The storming out, Aronson suggests, was probably calculated: his father had a gambling 
addiction and his departure allowed him to spend the evening with his cronies.

Aronson's achievements are remarkable given the family's poverty, the anti-Semitism and bullying he experienced, and his early mediocre academic record. He describes his childhood in Revere, Massachusetts, with an eye for good stories and controlled recollection. His elder brother Jason outgoing, clever and socially graceful - was everything that the younger Aronson was not, although his early hatred for him transmuted into affection and then, after Jason's premature death from cancer, into wistful family reflections. Aronson's younger sister is largely absent from his account.

Aronson keeps his youthful idealism closely under wraps, but his later career offered many opportunities for socially informed activity. While he was lecturing at the University of Texas in the 1960s, racial integration was of great significance and provoked high emotions. Aronson and his colleagues devised in the early 1970s a new method of classroom teaching for school children called the jigsaw technique. Small sets of students, containing children from different racial and ethnic backgrounds, and of different gender and ability, each cooperate in putting together part of the answer to a larger "Aronson offers question that the a revealing whole class has been portraitboth posed. The strategy of himself improved relations and of social between children psychology in the United States during the past halfcentury." of different races and backgrounds, and enhanced the academic performance of the disadvantaged children. After the system was eventually appreciated by educationalists, Aronson spent much time conducting classes for school teachers.

Today, macular degeneration has rendered Aronson almost totally blind, with the consequence that this book was an oral production. His greatest stated regret is that he can no longer distinguish his grandchildren by sight, although he did help one of them to learn to read.

Autobiographies are often carefully crafted, revealing only what the subject wishes to be known. Aronson, however, is happy to describe himself, warts and all. In doing so, he offers a revealing portrait both of himself and of social psychology in the United States during the past halfcentury.

W. F. Bynum is emeritus professor of the history of medicine at University College London, UK.

e-mail:w.bynum@ucl.ac.uk

\section{Books in brief}

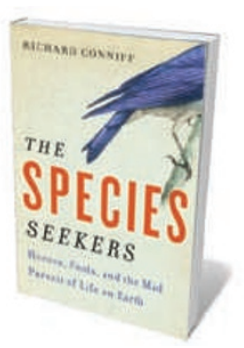

The Species Seekers: Heroes, Fools, and the Mad Pursuit of Life on Earth

Richard Conniff W. W. NORTON 464 pp. £19.99 (2010)

Celebrating the explorers who have scoured the planet for new forms of life, naturalist and writer Richard Conniff highlights how new discoveries generate scientific breakthroughs. He argues that the same spirit of adventurous curiosity that drove Swedish botanist Carl Linnaeus to derive his nomenclature of species and that spurred Charles Darwin to unearth evidence for evolution is in scientists today, as they hunt for creatures new to science in remote corners of Earth.

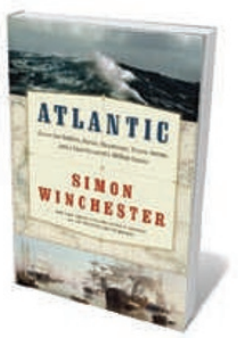

Atlantic: Great Sea Battles, Heroic Discoveries, Titanic Storms, and a Vast Ocean of a Million Stories

Simon Winchester HARPER 512 pp. \$27.99 (2010)

Simon Winchester's magisterial biography of the Atlantic Ocean portrays it both as a planetary feature and as a human stage - the "inland sea of Western civilization" along whose coasts humans have settled and traded for millennia. From its early navigation by the Norse and European sailors, to its setting for the slave trade and warfare, he recognizes the ocean's autonomous power. He also notes how its waters are changing as a result of pollution, overfishing and climate change.

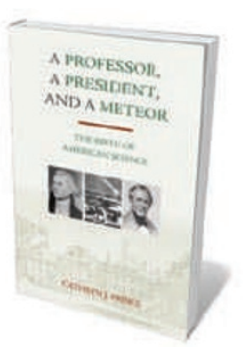

\section{A Professor, a President, and a Meteor: The Birth of American} Science

Cathryn J. Prince Prometheus Books 304 pp. \$26 (2010)

A meteor that lit up the sky in Weston, Connecticut, in 1807 sparked more than local consternation. It inspired Benjamin Silliman, a young chemistry professor at nearby Yale College, to analyse the meteorite's minerals. The controversy surrounding his hypothesis that it came from space triggered the rise of rigorous science in the United States. Cathryn Prince describes Silliman's life, his brushes with politics - including a spat with President Thomas Jefferson and his other discoveries, among them the distillation of petroleum.

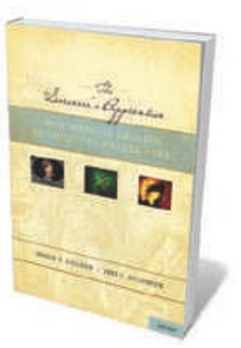

The Sorcerer's Apprentice: How Medical Imaging Is Changing Health Care

Bruce Hillman and Jeff Goldsmith OXFORD UNIV. PRESS 264 pp. $£ 27.95$ (2010)

Medical imaging has transformed health care, but its diagnostic value is balanced by its expense. Hillman and Goldsmith examine how scanning technologies such as magnetic resonance imaging and computed axial tomography are transforming radiology and yet putting pressure on budgets. They raise questions about economic incentives and the role of preventative medicine in promoting the uptake of scanning technology above other clinical necessities.

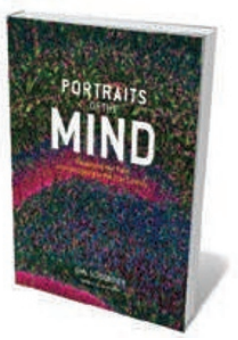

Portraits of the Mind: Visualizing the Brain from Antiquity to the 21st Century

Carl Schoonover ABRAMS 240 pp. \$35 (2010)

The human brain remains maddeningly complex. The intricacy of its structures is revealed by the striking pictures in this collection by neuroscientist Carl Schoonover. From medieval sketches and nineteenth-century drawings to state-of-the art scans, he explains how our depictions of brain regions, neurons, axons and dendrites have developed throughout history. It is a fascinating visual insight into neuroscience. 